\title{
Spatial variation in coda $Q$ and stressing rate around the Atotsugawa fault zone in a high strain rate zone, central Japan
}

\author{
Yoshihiro Hiramatsu ${ }^{1}$, Akihiro Sawada ${ }^{1}$, Yoritaka Yamauchi ${ }^{2}$, Shingo Ueyama ${ }^{2}$, Kin' ya Nishigami $^{3}$, Eiji Kurashimo ${ }^{4}$, \\ and the Japanese University Group of the Joint Seismic Observations at NKTZ \\ ${ }^{1}$ School of Natural System, College of Science and Engineering, Kanazawa University, Kakuma, Kanazawa, Ishikawa 920-1192, Japan \\ ${ }^{2}$ Department of Earth Sciences, Faculty of Science, Kanazawa University, Kakuma, Kanazawa, Ishikawa 920-1192, Japan \\ ${ }^{3}$ Disaster Prevention Research Institute, Kyoto University, Gokasho, Uji, Kyoto 611-0011, Japan \\ ${ }^{4}$ Earthquake Research Institute, The University of Tokyo, 1-1-1 Yayoi, Bunkyo-ku 113-0032, Japan
}

(Received May 16, 2012; Revised July 27, 2012; Accepted August 1, 2012; Online published March 6, 2013)

\begin{abstract}
We investigated a detailed spatial distribution of coda $Q$ around the Atotsugawa fault zone in a high strain rate zone, central Japan, using waveform data from dense seismic observations. Low coda $Q$ at lower frequencies is localized along the fault zone, showing a good spatial correlation with a low velocity zone in the lower crust. On the other hand, we find no characteristic spatial pattern of coda $Q$ at higher frequencies. The spatial correlation between the low coda $Q$ at the lower frequencies, and the low velocity zone, suggests that ductile deformations below the brittle-ductile transition zone in the crust contribute to the variation in coda $Q$ at lower frequencies. We estimated a spatial variation in the stressing rate of $15-18 \mathrm{kPa} / \mathrm{year}$ in the crust from that of coda $Q$ in the analyzed region. This value is greater than that estimated from GPS data. We conclude, therefore, that a high deformation rate below the brittle-ductile transition zone causes the high stressing rate, which results in the high strain rate along the fault zone observed by GPS.
\end{abstract}

Key words: Stressing rate, coda $Q$, brittle-ductile transition zone, high strain rate zone.

\section{Introduction}

Monitoring the state of stress and strain in the crust is important for elucidating the generation processes of a large inland earthquake. GPS observation is a powerful tool for examining the strain field on the surface. Seismic waves provide information related to stress in the crust. The stress field controls the distribution of micro-cracks in the crust, modulating the scattering of seismic waves, seismic wave velocity, and its anisotropy. Coda $Q$, or coda $Q^{-1}\left(Q_{C}^{-1}\right)$, which characterizes the scattering property, is regarded to be as good an indicator of the state of stress in the crust (Aki, 1980; Hiramatsu et al., 2000). In fact, some researchers have reported a temporal change in coda $Q$ because of a static stress change caused by a large earthquake (e.g., Hiramatsu et al., 2000).

A dense network of GPS sensors in Japan has revealed a zone of high strain rate concentration from Niigata to Kobe, designated as the Niigata-Kobe Tectonic Zone (Sagiya et al., 2000). In this zone, the strain rate is one order of magnitude larger than that of surrounding areas (Sagiya et al., 2000). In north-central Japan, the high strain rate zone includes many Quaternary active faults and volcanoes (Fig. 1). Historically, large earthquakes have occurred in this zone. This zone is also characterized seismically by a low velocity in the lower crust (Nakajima and Hasegawa,

Copyright (C) The Society of Geomagnetism and Earth, Planetary and Space Sciences (SGEPSS); The Seismological Society of Japan; The Volcanological Society of Japan; The Geodetic Society of Japan; The Japanese Society for Planetary Sciences; TERRAPUB.

doi:10.5047/eps.2012.08.012
2007; Matsubara et al., 2008), low coda $Q$ at lower frequencies (Jin and Aki, 2005), and a stress-induced shear wave polarization anisotropy (Hiramatsu et al., 2010).

Jin and Aki (2005) showed that low coda $Q$ for 1-2 $\mathrm{Hz}$ and $2-4 \mathrm{~Hz}$ frequency bands corresponded spatially to the high strain rate zone from an analysis of Hi-net data. However, the spatial resolution of their result is not sufficiently high to investigate detailed relations between the Atotsugawa fault zone, the low velocity zone, and the high strain rate zone through coda $Q$. The Japanese University Group of the Joint Seismic Observations at NKTZ commenced seismic observations around the Atotsugawa fault zone, central Japan, in 2004, with a dense distribution of seismic stations (Japanese University Group of the Joint Seismic Observations at NKTZ, 2005) (Fig. 2).

This study investigates details of the spatial distribution of coda $Q$ around the Atotsugawa fault zone and examines the relation between the spatial distributions of coda $Q$ and shear wave velocity in the lower crust. We also estimate the spatial variation in the stressing rate in the crust from the spatial distribution of coda $Q$.

\section{Data and Method}

We use seismic waveform data recorded at stations of the Japanese University Group of the Joint Seismic Observations at NKTZ, Earthquake Research Institute, The University of Tokyo, Disaster Prevention Research Institute, Kyoto University, Nagoya University, Japan Meteorological Agency, and Hi-net data operated by the National Research Institute for Earth Science and Disaster Prevention around 


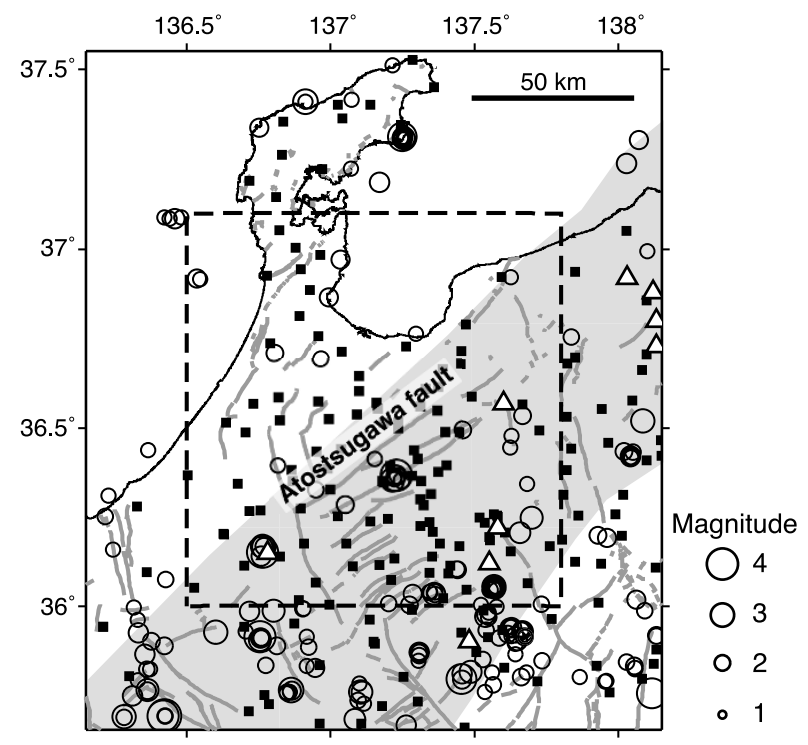

Fig. 1. Distributions of Quaternary active faults (gray lines) and Quaternary active volcanoes (triangles) in northern central Japan. The shaded area shows a high strain rate zone called the NKTZ. Squares and circles respectively show distributions of stations and earthquakes used for this study. A rectangle with dashed lines shows the area in which we construct coda $Q^{-1}$ maps (Fig. 3).

the Atotsugawa fault zone (Fig. 1). We specifically examine the spatial distribution of coda $Q$ around the Atotsugawa fault zone, shown in a rectangle with dashed lines in Fig. 1. To draw a precise map near the boundaries, we used stations and events outside the rectangle. We analyzed 249 events during the period November 2004-December 2006, of magnitudes greater than 1.8 , with depths shallower than $30 \mathrm{~km}$ (Fig. 1). For each station, we select events for which epicentral distances are within $30 \mathrm{~km}$ for the analysis of coda $Q$.

We apply a band-pass filter with center frequencies $f$ of $1.5,2.0,3.0,4.0,5.0,6.0,7.0,8.0,12.0$, and $24.0 \mathrm{~Hz}$ to the waveform data of each component, two horizontals and a vertical. Each band ranges from $0.8 f$ to $1.2 f$. Subsequently, we calculate the root-mean-square (RMS) amplitude in a moving time window with a duration of $4 / f$ for each frequency band. We then apply the single isotropic scattering model (Sato, 1977):

$$
\ln A_{C}(f \mid t)=-\ln t-\pi Q_{C}(f)^{-1} f t+\text { const, }
$$

where $A_{C}(f \mid t)$ is the RMS amplitude of band-pass-filtered coda waves at a center frequency of $f$ and a lapse time of $t$. Coda $Q^{-1}$ is calculated using fitting Eq. (1) for each frequency band and averaging over three components. However, a simple least squares method is inappropriate to fit Eq. (1) to $A_{C}(f \mid t)$ for the estimation of coda $Q^{-1}$ because reflected phases occasionally disturb the monotonous coda decay, providing an unstable estimation of coda $Q^{-1}$. We apply a robust estimation by the criteria of the least absolute deviation to estimate coda $Q^{-1}$ using Eq. (1) (Hiramatsu et al., 2000). A time window for the estimation of coda $Q^{-1}$ is from twice that of the $S$-wave travel time to the lapse time of $30 \mathrm{~s}$ after the origin time. If the coda tail is shorter than $30 \mathrm{~s}$, then the end of the time window is set to the time when the amplitude reaches twice the noise level for each frequency band. An example of the analysis is presented in Fig. 2.

Finally, we use the averaged logarithmic value of coda $Q^{-1}$ over earthquakes for each station. However, we eliminate stations for which the analyzed event number is less than 4 . We have checked apparent variations in coda $Q^{-1}$ that depend on data such as the source depth and lapse time. However, we found little variation with those factors.

\section{Spatial Variation in Coda $Q$}

We constructed a map of coda $Q^{-1}$ around the Atotsugawa fault zone using spatial smoothing of 10 minutes $\times 10$ minutes at 1 minute squares in longitude and latitude to examine details of the spatial variation in the analyzed area (Fig. 3). At lower frequency bands of 1.5-2 Hz, a low coda $Q$ zone is found along the Atotsugawa fault zone. This pattern of the low coda $Q$ zone fades gradually into the background at frequency bands of 3-4 Hz. However, at bands of frequencies higher than $5 \mathrm{~Hz}$, it is difficult to find a pattern that is related closely to the fault zone or the high strain rate zone. The spatial variation in coda $Q$ that corresponds to both the Atotsugawa fault zone and the NKTZ is, therefore, distinct at the lower frequency bands.

Recently, Nakajima et al. (2010) conducted seismic tomography to reveal the seismic velocity structure underlying the high strain rate zone. They reported a low velocity zone in the lower crust along the high strain rate zone. This spatial distribution of the low velocity zone apparently corresponds to that of low coda $Q$ at lower frequencies. We compared the values of coda $Q$ at frequency bands of 1.5 and $2.0 \mathrm{~Hz}$ to the perturbation of the $S$-wave velocity $\left(\delta V_{S}\right)$ at $25-\mathrm{km}$ depth, because coda waves mainly consist of $S$ waves (Fig. 4). For a comparison of these parameters, we resampled the data every 15 minutes in longitude and every 10 minutes in latitude (Fig. 3). A clear positive correlation was found between $\delta V_{S}$ and the coda $Q$ at frequency bands of 1.5 and $2.0 \mathrm{~Hz}$ (Fig. 4). In other words, the lower velocity corresponds to the lower coda $Q$ and vice versa. The correlation coefficient, $R$, is 0.67 at $1.5 \mathrm{~Hz}$ and 0.72 at $2.0 \mathrm{~Hz}$. We also compared these parameters at $0-\mathrm{km}, 5-\mathrm{km}, 10-\mathrm{km}$, $15-\mathrm{km}$, and $40-\mathrm{km}$ depths. However, no better correlation than that at $25 \mathrm{~km}$ was found (Fig. 4). The correlation coefficients at $25 \mathrm{~km}$ of both frequency bands show the highest value with the lowest $p$-value, meaning that the correlation shows the greatest significance at $25 \mathrm{~km}$. Here, the $p$-value shows the probability that we would have obtained the current result if the correlation coefficient were, in fact, zero. These facts imply that the spatial distribution of coda $Q$ at lower frequencies can be attributed to the lower crust.

\section{Spatial Variation in Stressing Rate Estimated from Coda $Q$}

Hiramatsu et al. (2010) have proposed a new method to estimate a spatial variation in the stressing rate in the crust using a spatial variation in shear wave splitting or coda $Q$. They obtained a variation in the stressing rate of $3 \pm 0.6 \mathrm{kPa} /$ year in the brittle upper crust, and that of $13 \pm 3.5$ $\mathrm{kPa} /$ year in the ductile part below the brittle-ductile transition zone in the crust, in the NKTZ. We have described 
(a) 2005/03/24 20:12:34 (JST) Lon: $137.2318^{\circ} \mathrm{E}$ Lat: $36.3685^{\circ} \mathrm{N}$ Dep: $11.22 \mathrm{~km} \mathrm{M} 2.7$

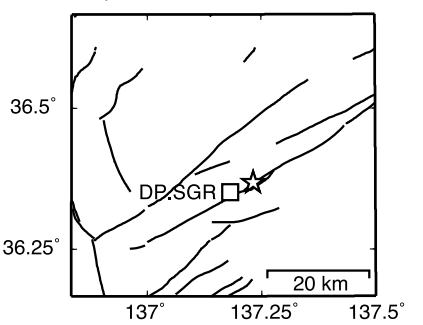

(b) $\quad \times 10^{-3}$
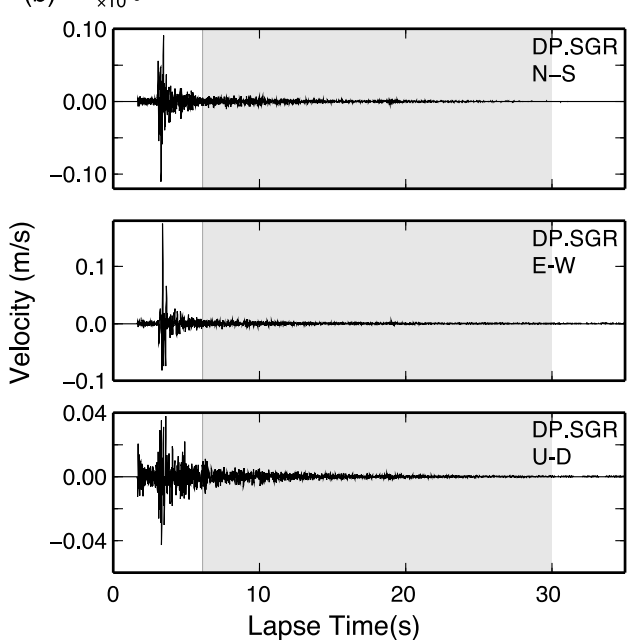

(c)
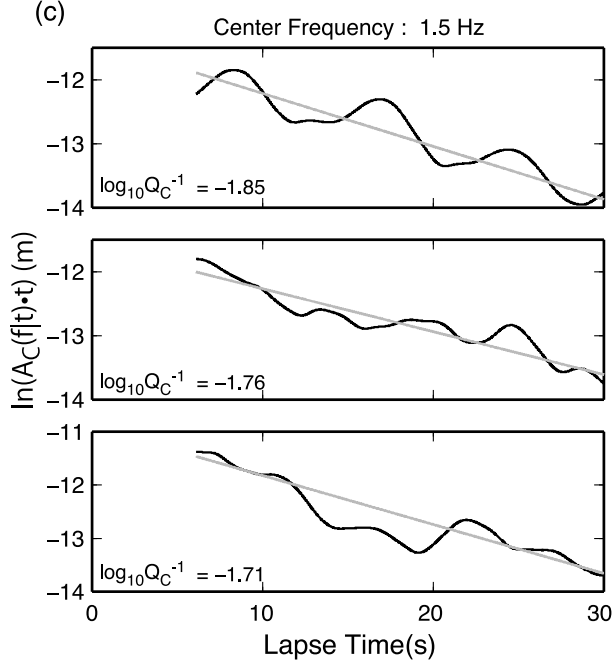

Fig. 2. Example of the estimation of coda $Q^{-1}$. (a) Locations of an epicenter (star) and a station (square). Lines show Quaternary active faults. (b) Velocity waveforms of three components recorded at the station in (a). Hatched parts are time windows shown in (c). (c) Fitting of Eq. (1) (gray lines) to RMS amplitudes (black lines) at the $1.5 \mathrm{~Hz}$ frequency band.
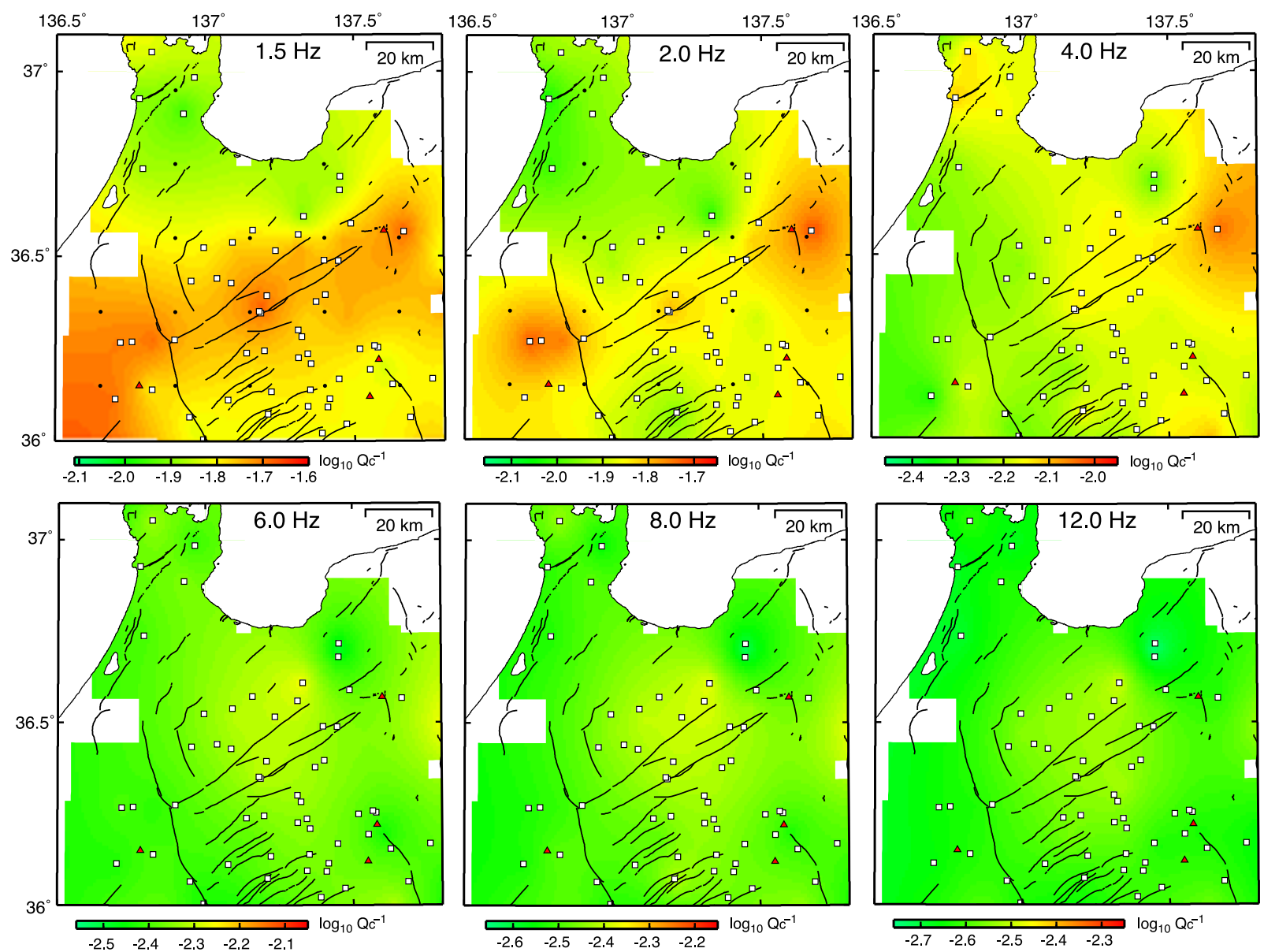

Fig. 3. Examples of the spatial distribution of coda $Q^{-1}$. Squares are stations used to draw maps, lines show Quaternary active faults, and triangles show Quaternary active volcanoes. Circles are the points at which we sample values of coda $Q, \delta V_{S}$, and the differential strain rate for Fig. 4 .

details of the distribution of coda $Q$ around the Atotsugawa fault zone in the previous section. It is, therefore, interesting to compare the spatial variation in the stressing rate around the Atotsugawa fault zone to that of the average in the NKTZ.

We estimate a spatial variation in the stressing rate around the Atotsugawa fault zone, $\dot{\sigma}$, from coda $Q$ as

$$
\dot{\sigma}=\frac{1}{R S C_{Q_{C}}} \frac{\Delta Q_{C}}{Q_{C}} \frac{1}{T_{C}},
$$

where $\Delta Q_{C} / Q_{C}$ is the fraction of the spatial variations in coda $Q, R S C_{Q_{C}}$ is the response of coda $Q$ to a step-wise 

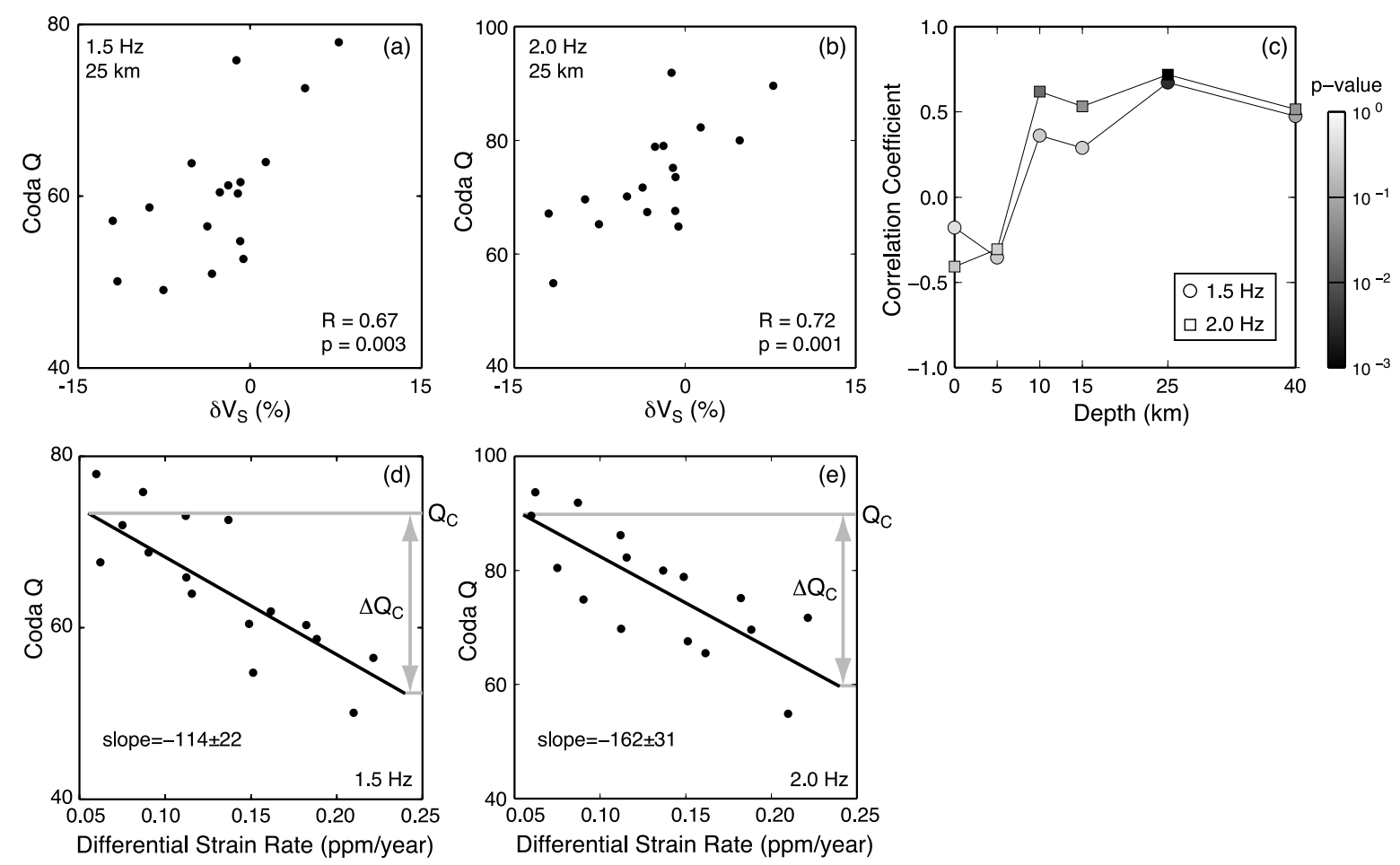

Fig. 4. (a) Plot of $\delta V_{S}$ (Nakajima et al., 2010) versus the coda $Q$ at $1.5 \mathrm{~Hz}$ frequency band and (b) that at $2.0 \mathrm{~Hz}$ frequency band. $R$ shows the correlation coefficient and $p$ denotes the $p$-value. (c) Plot of the depth of $\delta V_{S}$ versus the correlation coefficient. A gray scale shows the $p$-value. (d) Plot of the differential strain rate (Sagiya et al., 2000) versus the coda $Q$ at the $1.5 \mathrm{~Hz}$ frequency band, and (e) that at the $2.0 \mathrm{~Hz}$ frequency band.

stress change, and $T_{C}$ is the characteristic time of the stress accumulation in the crust (Hiramatsu et al., 2010). This formulation is based on the following two ideas: a constant stressing rate is approximated by a successive stepwise stress change with a constant time interval, and a variation in the condition of cracks attributable to the step-wise stress change recovers to a steady-state during the constant time interval. In other words, a steady state crack condition, which is represented by the value of coda $Q$, is controlled by the amount of the step-wise stress change and the constant time interval, which is the stressing rate (Hiramatsu et al., 2010). Therefore, we can estimate $\dot{\sigma}$ from $\Delta Q_{C} / Q_{C}$.

Following Hiramatsu et al. (2010), we adopt $R S C_{Q_{C}}=$ $10(\mathrm{MPa})^{-1}$ based on the temporal change in coda $Q$ in the Tamba region, attributable to the static stress change induced by the 1995 Hyogo-ken Nanbu earthquake, Japan (Hiramatsu et al., 2000), and $T_{C}=2$ years from the observations of the recovery of crack conditions to the step-wise static stress change (Hiramatsu et al., 2005; Sugaya et al., 2009). A linear trend showing the relation between coda $Q$ and the differential strain rate is used to evaluate $\Delta Q_{C} / Q_{C}$ (Fig. 4). We sample the strain rate at the same points of coda $Q$ and $\delta V_{S}$ using an interpolation of the strain rate (Sagiya et al., 2000). The differential strain rate is calculated by subtracting the strain rate of the compression axis from that of the extension axis. We recognize a negative correlation between coda $Q$ and the differential strain rate, indicating a lower coda $Q$ with a higher differential strain rate. We obtained $\Delta Q_{C} / Q_{C}=0.31$ at $1.5 \mathrm{~Hz}$, and $\Delta Q_{C} / Q_{C}=0.38$ at $2.0 \mathrm{~Hz}$ (Fig. 4). Substituting these values into Eq. (2), the variation in the stressing rate is estimated to be $15 \pm 3$ $\mathrm{kPa} /$ year at $1.5 \mathrm{~Hz}$ and $18 \pm 4 \mathrm{kPa} /$ year at $2.0 \mathrm{~Hz}$ in the an- alyzed region. These values are larger than the spatial variation in the stressing rate of $3 \mathrm{kPa} /$ year in the NKTZ estimated from GPS data (Hiramatsu et al., 2010). However, if the adopted values of $R S C_{Q_{C}}$ and $T_{C}$ differ greatly from the real ones, then this discrepancy might disappear. For example, if the product of $R S C_{Q_{C}}$ and $T_{C}$ is 5-6 times larger than the adopted one, then we might obtain a compatible stressing rate with that estimated from the GPS data, although we have no evidence for that supposition.

\section{Discussion}

Coda waves are regarded as reflecting the state of stress in the whole crust from a sampling area. The creep model (Jin and Aki, 1989), and the comparison of the recovery process of coda $Q$ to a step-wise static stress change with seismicity (Sugaya et al., 2009), emphasize that the variation in coda $Q$ reflects a change in the ductile fracture in the brittle-ductile transition zone in the crust. The spatial correspondence between the low coda $Q$ zone obtained in this study, and the low velocity zone in the lower crust from seismic tomography (Fig. 4), supports that the observed coda $Q$ represents a property primarily in the lower crust. If low $S$-velocities are associated with increased anelastic attenuation, then the correspondence is explainable by the spatial distribution of the anelastic attenuation. However, the strong frequency-dependent features of coda $Q$, observed during the course of this study, suggest that the variation in coda $Q$ reflects a variation in the scattering property, although we cannot reject completely the possibility that the frequency-dependent anelastic attenuation may cause the variation. We suggest, therefore, that the estimated variation in the stressing rate from coda $Q$ is caused by a varia- 
tion in the ductile deformation rate below the brittle-ductile transition zone in the crust. Based on this idea, the high sensitivity of coda $Q$ to the stressing rate at lower frequencies indicates the existence of a characteristic scale of ductile fractures that controls the ductile deformation rate under the loading stress. A numerical simulation showed that the scattering is most effective at $\lambda \approx 2 a$, where $\lambda$ is the wavelength and $a$ the characteristic length of the scatterer (Yomogida and Benites, 1995). The average $S$-wave velocity at $25-\mathrm{km}$ depth is about $3.5 \mathrm{~km} / \mathrm{s}$. The characteristic scale of the ductile fractures is thereby estimated to be about $1-2 \mathrm{~km}$.

Coda $Q$ has usually been regarded as a good indicator of the stress condition in the crust because a good spatial correlation exists between coda $Q$ and seismicity (Aki, 1980). We propose that coda $Q$ at lower frequencies is an indicator of the deformation rate below the brittle-ductile transition zone in the crust, causing a good spatial correlation between coda $Q$ and seismicity. Numerical simulations of the nucleation of large earthquakes have shown accelerated slips in the unstable-stable transition zone, that is the brittleductile transition zone, over a period of several years before the respective earthquakes occurred (e.g., Shibazaki and Iio, 2003). The accelerated slip causes the high strain rate in the surrounding area. The possibility exists that coda $Q$ detects such a temporal variation in the strain rate because coda $Q$ at lower frequencies is sensitive to a variation in the strain rate, as shown in this study.

\section{Conclusions}

Dense seismic observation around the Atotsugawa fault zone, in a high strain rate zone, central Japan, shows low coda $Q$ at lower frequencies along the fault zone and no characteristic spatial distribution of coda $Q$ at higher frequencies. The spatial variation in coda $Q$ coincides with that in low velocity in the lower crust estimated by seismic tomography. The spatial variation in the stressing rate in the analyzed region is estimated from the spatial distribution of coda $Q$ at lower frequencies. We obtain a spatial variation in the stressing rate of $15-18 \mathrm{kPa}$ /year, showing a larger value than that estimated from GPS data. These features can be interpreted according to the high deformation rate below the brittle-ductile transition zone along the Atotsugawa fault zone.

Acknowledgments. We thank the National Research Institute for Earth Science and Disaster Prevention and the Japan Meteorological Agency for allowing us to use waveform data collected at each online station. We are grateful to Junichi Nakajima for providing us with seismic tomography data. We also thank Haruo Sato and an anonymous reviewer, for useful comments. All figures were made using GMT software (Wessel and Smith, 1998). This research was partly supported by a grant offered under the Earthquake Prediction Research program of the Ministry of Education, Culture, Sports, Science and Technology of Japan.

\section{References}

Aki, K., Scattering and attenuation of shear waves in the lithosphere, $J$. Geophys. Res., 85, 6496-6504, 1980.

Hiramatsu, Y., N. Hayashi, M. Furumoto, and H. Katao, Temporal changes in coda $Q^{-1}$ and $b$-value due to the static stress change associated with the 1995 Hyogo-ken Nanbu earthquake, J. Geophys. Res., 105, 6141$6151,2000$.

Hiramatsu, Y., H. Honma, A. Saiga, M. Furumoto, and T. Ooida, Seismological evidence on characteristic time of crack healing in the shallow crust, Geophys. Res. Lett., 32, L09304, doi:10.1029/2005GL022657, 2005.

Hiramatsu, Y., K. Iwatsuki, S. Ueyama, T. Iidaka, and the Japanese University Group of the Joint Seismic Observations at NKTZ, Spatial variation in shear wave splitting of the upper crust in the zone of inland high strain rate, central Japan, Earth Planets Space, 62, 675-684, 2010.

Jin, A. and K. Aki, Spatial and temporal correlation between coda $Q^{-1}$ and seismicity and its physical mechanism, J. Geophys. Res., 94, 1404114059, 1989.

Jin, A. and K. Aki, High-resolution maps of Coda $Q$ in Japan and their interpretation by the brittle-ductile interaction hypothesis, Earth Planets Space, 57, 403-409, 2005.

Matsubara, M., K. Obara, and K. Kasahara, Three-dimensional P- and Swave velocity structures beneath the Japanese Islands obtained by highdensity seismic stations by seismic tomography, Tectonophysics, $\mathbf{4 5 4}$, 86-103, 2008

Nakajima, J. and A. Hasegawa, Deep crustal structure along the NiigataKobe Tectonic Zone, Japan: Its origin and segmentation, Earth Planets Space, 59, e5-e8, 2007.

Nakajima, J., A. Kato, T. Iwasaki, S. Ohmi, T. Okada, T. Takeda, and the Japanese university group of the joint seismic observations at NKTZ, Earth Planets Space, 62, 555-566, 2010.

Sagiya, T., S. Miyazaki, and T. Tada, Continuous GPS array and presentday crustal deformation of Japan, Pure Appl. Geophys., 157, 20032322, 2000.

Sato, H., Energy propagation including scattering effects: Single isotropic scattering approximation, J. Phys. Earth, 25, 27-41, 1977.

Shibazaki, B. and Y. Iio, On the physical mechanism of silent slip events along the deeper part of the seismogenic zone, Geophys. Res. Lett., 30, doi:10.1029/2003GL017047, 2003.

Sugaya, K., Y. Hiramatsu, M. Furumoto, and H. Katao, Coseismic change and recovery of scattering environment in the crust after the 1995 Hyogo-ken Nanbu earthquake, Japan, Bull. Seismol. Soc. Am., 99, 435440, 2009.

The Japanese University Group of the Joint Seismic Observations at the Niigata-Kobe Tectonic Zone, The Japanese University Joint Seismic Observations at NKTZ, Bull. Earthq. Res. Inst., 80, 133-147, 2005 (in Japanese with English abstract).

Wessel, P. and W. H. F. Smith, New, improved version of Generic Mapping Tools released, Eos Trans. AGU, 79, 579, 1998.

Yomogida, K. and R. Benites, Relation between direct wave $Q$ and coda $Q$ : A numerical approach, Geophys. J. Int., 123, 471-483, 1995.

Y. Hiramatsu (e-mail: yoshizo@hakusan.s.kanazawa-u.ac.jp), A. Sawada, Y. Yamauchi, S. Ueyama, K. Nishigami, E. Kurashimo, and the Japanese University Group of the Joint Seismic Observations at NKTZ 